Provided for non-commercial research and education use. Not for reproduction, distribution or commercial use.

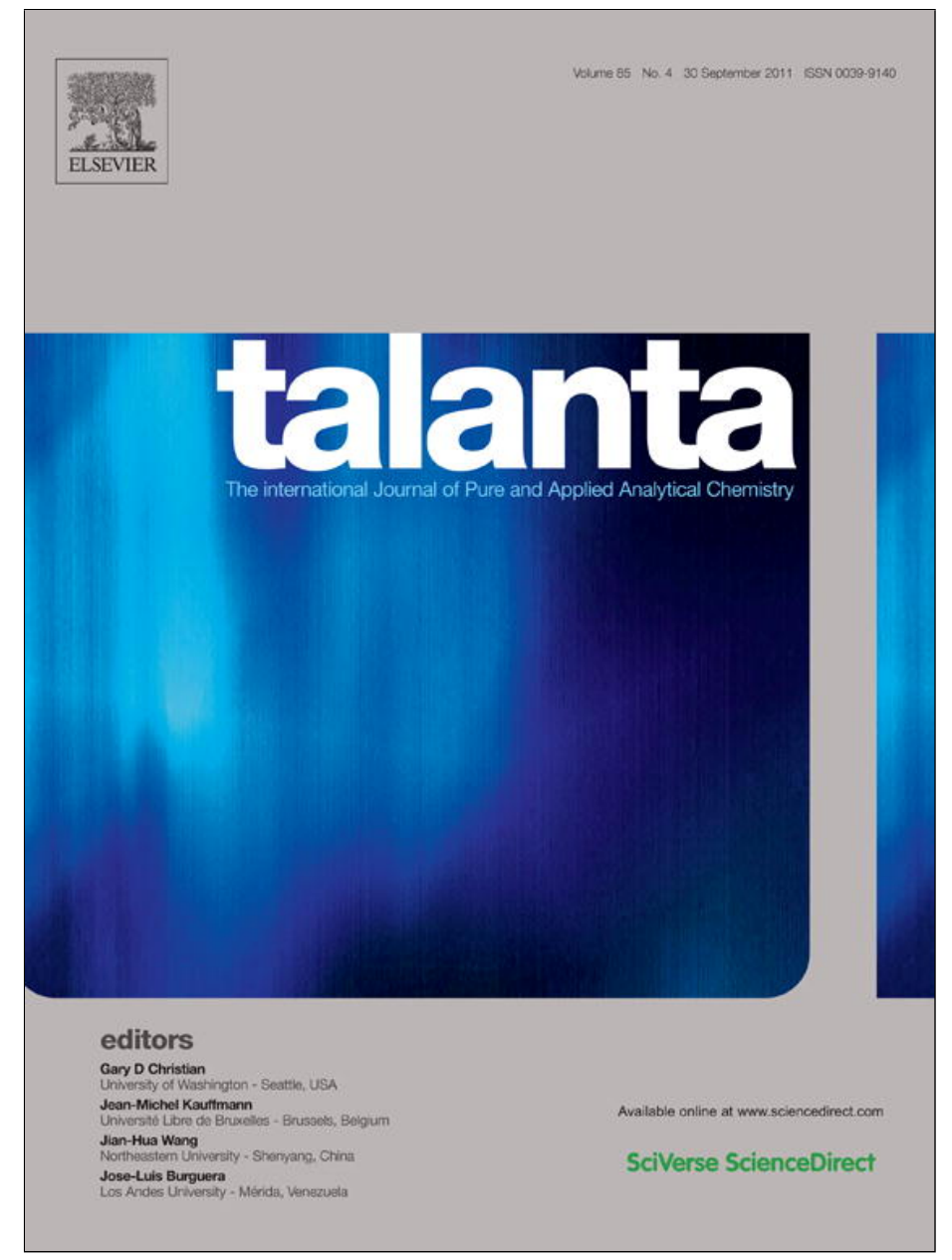

This article appeared in a journal published by Elsevier. The attached copy is furnished to the author for internal non-commercial research and education use, including for instruction at the authors institution and sharing with colleagues.

Other uses, including reproduction and distribution, or selling or licensing copies, or posting to personal, institutional or third party websites are prohibited.

In most cases authors are permitted to post their version of the article (e.g. in Word or Tex form) to their personal website or institutional repository. Authors requiring further information regarding Elsevier's archiving and manuscript policies are encouraged to visit:

http://www.elsevier.com/copyright 


\title{
Multivariate analysis of the polyphenol composition of Tempranillo and Graciano red wines
}

\author{
Matilde García-Marino, José Miguel Hernández-Hierro, Celestino Santos-Buelga, \\ Julián C. Rivas-Gonzalo, M. Teresa Escribano-Bailón* \\ Grupo de Investigación en Polifenoles, Unidad de Nutrición y Bromatología, Facultad de Farmacia, Universidad de Salamanca, Campus Miguel de Unamuno, E 37007 Salamanca, Spain
}

\section{A R T I C L E I N F O}

\section{Article history:}

Received 8 March 2011

Received in revised form 7 July 2011

Accepted 9 July 2011

Available online 23 July 2011

\section{Keywords:}

Wine

Colour

Chemometrics

Tempranillo

Graciano

Polyphenols

\begin{abstract}
A B S T R A C T
Vitis vinifera L. $c v$ Graciano is often used as a blending partner of Tempranillo based wines because it is considered to contribute significantly to the quality. The aim of this study is to discriminate between Tempranillo and Graciano monovarietal wines, and those made by the incorporation of $20 \%$ of Graciano variety in two different stages (at the end of malolactic fermentation and mixing the two grape varieties in the pre-fermentative maceration stage) of the winemaking process of the Tempranillo variety. To achieve this, supervised and unsupervised pattern recognition tools were applied to the data obtained in the study of the detailed polyphenolic composition, colour and other oenological parameters (143 variables). Patterns related to stages in the winemaking and ageing process, different wines and vintages can be observed using principal component analyses. Furthermore, linear discriminant analysis has been applied in order to characterise the wine samples. From the 143 variables, flavan-3-ols have exerted a profound influence on wine differentiation.
\end{abstract}

(C) 2011 Elsevier B.V. All rights reserved.

\section{Introduction}

Vitis vinifera L. $c v$ Graciano represents only a small proportion of the total grapes grown in Spain. In the Rioja region this variety is commonly used as a blending partner of Tempranillo-based wines to which it adds brightness, aroma, tannins and acidity. Although less usual some wineries also produce varietal Graciano wines. Differences in the phenolic profiles between Graciano and Tempranillo have been studied [1-3] and it has been shown that flavanols from grape skins of Graciano are more effective copigments of anthocyanins than those of Tempranillo, and the opposite occurs for seed flavanols, where Tempranillo was more effective [2]. On the other hand, it has been proposed that copigmentation could assist the extraction of polyphenolics from grapes [4] and that it could also act as a first stage in the formation of new pigments that determine the colour of aged red wines [5]. Taking into consideration the aforementioned, it could be reasonably expected that if the contact of the fermenting must with the skins and seeds of both varieties was facilitated, the final wine could result in higher contents of some polyphenolics, which would affect not only the sensorial properties but also its ageing potential.

Nowadays the use of techniques such as HPLC-DAD coupled to $\mathrm{ESI} / \mathrm{MS}^{n}$ allows the determination of a large quantity of phenolic

\footnotetext{
* Corresponding author. Tel.: +34 923294 537; fax: +34 923294515

E-mail address: escriban@usal.es (M.T. Escribano-Bailón).
}

compounds in red wines [6]. The huge amount of data that can be obtained makes the use of chemometry a necessary approach to help selecting relevant information [7-9]. Chemometric tools have been used in a wide range of foods $[10,11]$ including wine [12]. Specifically, the phenolic composition, colour and oenological parameters of wine have been studied using different procedures for classificatory purposes and for recognising grape cultivars [13-20] and also for studying the relationship between the colour and phenolic composition of red wines obtained under different winemaking conditions $[3,21,22]$.

The aim of this study is to discriminate between Tempranillo and Graciano varietal wines, and those made by both blending these wines at the end of malolactic fermentation and mixing the two grape varieties in the pre-fermentative maceration stage. To achieve this, supervised and unsupervised pattern recognition tools were applied to the data obtained in the study of the detailed polyphenolic composition, colour and other oenological parameters (143 variables). Also, the variables that can explain most of the variance observed in the dataset have been investigated.

\section{Experimental}

\subsection{Samples}

The wines used in this study were obtained from red grapes of $V$. vinifera L. of the Tempranillo and Graciano varieties, harvested in 2005 and 2006 and processed by Bodegas Roda (Haro, La Rioja, 
Table 1

Stages of sampling of wines T, G, M and W during winemaking and ageing.

\begin{tabular}{cll}
\hline & Stages & Time \\
\hline 1 & End of alcoholic fermentation & 16 days \\
2 & Middle of post-fermentative maceration & 20 days \\
3 & Beginning of malolactic fermentation & 22 days \\
4 & Middle of malolactic fermentation & 29 days \\
$5^{\text {a }}$ & End of malolactic fermentation & 39 days \\
6 & Before 1st rack & 3 moths \\
7 & Before 2nd rack & 6 moths \\
8 & Before 3rd rack & 12 moths \\
9 & Clarification and bottling & 14 moths \\
10 & Ageing in bottle during 5 months & 602 days \\
11 & Ageing in bottle during 9 months & 736 days \\
12 & Ageing in bottle during 12 months & 827 days \\
\hline
\end{tabular}

a In the case of $\mathrm{W}$ wines samples, were collected from stage 05.

Spain). In the studied samples notations $\mathrm{T}$ and $\mathrm{G}$ were used to design Tempranillo and Graciano varietal wines respectively; W was the wine obtained by the blend of these wines (proportion 80:20) at the end of malolactic fermentation, and $\mathrm{M}$ the wine resulting of the covinification of the two grape varieties mixed in proportion 80:20 in the pre-fermentative maceration stage. Samples of each wine were collected in triplicate during winemaking and ageing (Table 1). The total number of wine samples collected was 264, 132 per vintage. Analysis of each sample was also performed in triplicate and the mean value obtained was used in the statistical treatment.

\subsection{Wine polyphenol analysis}

For the anthocyanins and flavonols analysis $1 \mathrm{~mL}$ of wine samples were diluted (1:1) with $0.1 \mathrm{~N} \mathrm{HCl}$ (Panreac ${ }^{\circledR}$ Barcelona, España), filtered through $0.45 \mu \mathrm{m}$ Millex ${ }^{\circledR}$ HV syringe driven filter units and injected into the chromatographic system. For the flavan-3-ols and phenolic acids analysis $2 \mathrm{~mL}$ of each wine sample diluted (1:1) with $0.1 \mathrm{~N} \mathrm{HCl}$ were eluted through Oasis ${ }^{\circledR} \mathrm{MCX} 3 \mathrm{~cm}^{3}$ (Waters Corporation Mildford, MA, USA) cartridges previously conditioned with $2 \mathrm{~mL}$ methanol and $2 \mathrm{~mL}$ water, with the objective of eliminating the red pigments [23]. After washing with $4 \mathrm{~mL}$ of ultrapure water, flavan-3-ols and the phenolic acids were eluted with $8 \mathrm{~mL}$ methanol, whereas anthocyanins and the flavonols were retained in the cartridges. A small volume of water was added to the eluate and concentrated under vacuum at lower than $30^{\circ} \mathrm{C}$ until complete elimination of methanol. The volume of the aqueous residue was adjusted to $0.5 \mathrm{~mL}$ with ultrapure water (Direct Q3, Millpore-Waters, Bedford, MA), filtered $(0.45 \mu \mathrm{m})$ and analysed by HPLC-DAD-MS. All analyses were performed in triplicate.

\subsection{HPLC-DAD-MS analysis}

The HPLC-DAD analysis was performed in a Hewlett-Packard 1100 series liquid chromatograph. The LC system was connected to the probe of the mass spectrometer via the UV cell outlet. The mass analyses were performed using a Finnigan ${ }^{\mathrm{TM}}$ LCQ ion trap detector (Thermoquest, San Jose, CA, USA) equipped with an API source, using an electrospray ionisation (ESI) interface. The HPLC-DAD-MS analysis conditions of red pigments and flavonols were carried out in accordance with García-Marino et al. [3] selecting an additional wavelength at $360 \mathrm{~nm}$ to achieve the analysis of flavonols. Analyses of flavan-3-ols and phenolic acids were carried out as described by García-Marino et al. [24] selecting an additional wavelength at $330 \mathrm{~nm}$ to achieve the analysis of phenolic acids.

\subsection{Quantification}

For the quantitative analysis, calibration curves were obtained using standards of anthocyanins (delphinidin, cyanidin, petuni-
Table 2

Pigments analysed.

\begin{tabular}{|c|c|}
\hline \multicolumn{2}{|c|}{ Pigments } \\
\hline 1 & $\begin{array}{l}\text { Direct condensation product between } \\
\text { malvidin-3-O-glucoside and gallocatechin }\end{array}$ \\
\hline 2 & Delphinidin-3,5-diglucoside \\
\hline 3 & $\begin{array}{l}\text { Direct condensation product between } \\
\text { petunidin-3-O-glucoside and catechin }\end{array}$ \\
\hline 4 & Petunidin-3,5-diglucoside \\
\hline 5 & Delphinidin-3,7-diglucoside \\
\hline 6 & Vitisin A of delphinidin-3-O-glucoside \\
\hline 7 & $\begin{array}{l}\text { Direct condensation product between } \\
\text { peonidin-3-O-glucoside and catechin }\end{array}$ \\
\hline 8 & $\begin{array}{l}\text { Direct condensation product between } \\
\text { malvidin-3-O-glucoside and catechin }\end{array}$ \\
\hline 9 & Delphinidin-3-O-glucoside \\
\hline 10 & Petunidin-3,7-diglucoside \\
\hline 11 & Cyanidin-3-O-glucoside \\
\hline 12 & Vitisin $\mathrm{A}$ of petunidin-3-O-glucoside \\
\hline 13 & Petunidin-3-O-glucoside \\
\hline 14 & Malvidin-3,7-diglucoside \\
\hline 15 & Vitisin A of peonidin-3-O-glucoside \\
\hline 16 & Peonidin-3-O-glucoside \\
\hline 17 & Vitisin A of malvidin-3-O-glucoside \\
\hline 18 & Malvidin-3-O-glucoside \\
\hline 19 & Delphinidin-3-O-(6'-acetyl)-glucoside \\
\hline 20 & Malvidin-3-O-hexose \\
\hline 21 & Vitisin B of malvidin-3-O-glucoside \\
\hline 22 & Malvidin-3-O-pentoside \\
\hline 23 & Malvidin-3-O-glucoside-8-ethyl-catechin \\
\hline 24 & Petunidin-3-O-(6'-acetyl)glucoside \\
\hline 25 & Malvidin-3-O-glucoside-8-ethyl-gallocatechin \\
\hline 26 & Malvidin-3-O-glucoside-8-ethyl-epicatechin \\
\hline 27 & Cyanidin-3-O-hexoside \\
\hline 28 & Malvidin-3-O-glucoside-8-ethyl-metoxicatechin \\
\hline 29 & $\begin{array}{l}\text { Malvidin-3-O-(6'-p-coumaroyl)glucoside-8-ethyl- } \\
\text { catechin }\end{array}$ \\
\hline 30 & Peonidin-3-O-(6'-acetyl)glucoside \\
\hline 31 & Vitisin A of malvidin-3-O-(6'-p-coumaroyl $)$ glucoside \\
\hline 32 & Malvidin-3-O-(6'-acetyl)glucoside \\
\hline 33 & Delphinidin-3-O-(6'-p-coumaroyl)glucoside \\
\hline 34 & Petunidin-3-O-(6'-p-coumaroyl)glucoside (cis) \\
\hline 35 & Malvidin-3-O-(6'-p-caffeoyl)glucoside \\
\hline 36 & Cyanidin-3-O-(6'-p-coumaroyl)glucoside \\
\hline 37 & Petunidin-3-O-(6'-p-coumaroyl)glucoside (trans) \\
\hline 38 & Malvidin-3-O-(6'-p-coumaroyl)glucoside (cis) \\
\hline 39 & Peonidin-3-O-glucoside-4-vinylcatechol \\
\hline 40 & Peonidin-3-O-(6'-p-coumaroyl)glucoside (trans) \\
\hline 41 & Malvidin-3-O-(6'-p-coumaroyl)glucoside (trans) \\
\hline 42 & Malvidin-3-O-glucoside-4-vinylphenol adduct \\
\hline 43 & Malvidin-3-O-glucoside-4-vinylguaiacol adduct \\
\hline 44 & $\begin{array}{l}\text { Malvidin-3-O-(6'-acetyl)glucoside-4-vinylphenol } \\
\text { adduct }\end{array}$ \\
\hline 45 & $\begin{array}{l}\text { Malvidin-3-O-(6'-p-coumaroyl)glucoside-4- } \\
\text { vinylphenol }\end{array}$ \\
\hline 46 & $\begin{array}{l}\text { Malvidin-3-O-(6'-p-coumaroyl)glucoside-4- } \\
\text { vinylguaiacol }\end{array}$ \\
\hline 47 & Total anthocyanidin-monoglucosides \\
\hline 48 & Total anthocyanidin-diglucosides \\
\hline 49 & Total acetyl anthocyanins \\
\hline 50 & Total caffeoyl anthocyanins \\
\hline 51 & Total $p$-coumaroyl anthocyanins \\
\hline 52 & Total vitisins \\
\hline 53 & Total vinyl anthocyanin adducts \\
\hline 54 & Total pyranoanthocyanidins \\
\hline 55 & $\begin{array}{l}\text { Acetaldehyde-mediated flavanol-anthocynidin } \\
\text { condensation products }\end{array}$ \\
\hline 56 & Direct flavanol-anthocyanin condensation products \\
\hline 57 & Total condensation products \\
\hline 58 & Total pigments \\
\hline 59 & Total anthocyanins \\
\hline 60 & Total acylated anthocyanins \\
\hline 61 & Total derived pigments \\
\hline 62 & A-type vitisins \\
\hline 63 & B-type vitisins \\
\hline 64 & Anthocyanin-4-vinylphenol adducts \\
\hline 65 & Anthocyanin-4-vinylcatechol adducts \\
\hline 66 & Anthocyanin-4-vinylguaiacol adducts \\
\hline
\end{tabular}


Table 3

Flavonols, flavan-3-ols, phenolic acids, chromatic parameters and other variables analysed.

\begin{tabular}{|c|c|c|c|c|c|c|c|c|c|}
\hline \multicolumn{2}{|c|}{ Flavonols } & \multicolumn{2}{|c|}{ Flavan-3-ols } & \multicolumn{2}{|c|}{ Phenolic acids } & \multicolumn{2}{|c|}{$\begin{array}{l}\text { Colorimetric } \\
\text { parameters }\end{array}$} & \multicolumn{2}{|c|}{ Other variables } \\
\hline 1 & Myricetin-3-O-galactoside & 1 & Procyanidin tetramer & 1 & Gallic acid & 1 & $L^{*}$ & 1 & $\mathrm{pH}$ \\
\hline 2 & Myricetin-3-O-glucoside & 2 & Procyanidin pentamer & 2 & Protocatechuic acid & 2 & $a^{*}$ & 2 & $\begin{array}{l}\text { Mean degree of } \\
\text { polymerisation } \\
(\mathrm{mDP})\end{array}$ \\
\hline 3 & Myricetin aglycone & 3 & (+)-gallocatechin & 3 & Vanillic acid & 3 & $b^{*}$ & 3 & \%Copigmentation \\
\hline 4 & Quercetin-3-O-galactoside & 4 & Procyanidin tetramer & 4 & Syringic acid & 4 & $C_{a b}^{*}$ & & \\
\hline 5 & Quercetin-3-O-glucoside & 5 & Procyanidin dimer (B1) & 5 & trans-Caftaric acid & 5 & $h_{a b}$ & & \\
\hline 6 & Quercetin glucuronide & 6 & Procyanidin dimer (B3) & 6 & cis-Cutaric acid & 6 & $s^{*}{ }_{u v}$ & & \\
\hline 7 & $\begin{array}{l}\text { Quercetin-7-O- } \\
\text { neohesperidoside-3-O- } \\
\text { rutinoside }\end{array}$ & 7 & Prodelphinidin dimer & 7 & trans-Cutaric acid & & & & \\
\hline 8 & Quercetin aglycone & 8 & (-)-Epigallocatechin & 8 & trans-Fertaric acid & & & & \\
\hline 9 & Kaempferol-3-O-galactoside & 9 & Procyanidin trimer & 9 & p-Coumaroyl hexose (1) & & & & \\
\hline 10 & Kaempferol-3-O-glucoside & 10 & Procyanidin trimer & 10 & trans-Caffeic acid & & & & \\
\hline 11 & Kaempferol aglycone & 11 & $(+)$-Catechin & 11 & p-Coumaroyl hexose (2) & & & & \\
\hline 12 & Isorhamnetin aglycone & 12 & Procyanidin tetramer & 12 & p-Coumaric acid & & & & \\
\hline 13 & Total flavonols & 13 & Procyanidin trimer & 13 & Total hydroxybenzoic acids & & & & \\
\hline 14 & Total myricetin derivatives & 14 & Procyanidin dimer (B4) & 14 & Total hydroxycinnamic acids & & & & \\
\hline 15 & Total quercetin derivatives & 15 & Procyanidin dimer (B6) & 15 & Total phenolic acids & & & & \\
\hline 16 & Total kaempferol derivatives & 16 & Procyanidin dimer (B2) & & & & & & \\
\hline 17 & Total isorhamentin derivatives & 17 & (-)-Epicatechin & & & & & & \\
\hline 18 & Total myricetin glycosides & 18 & Procyanidin trimer & & & & & & \\
\hline 19 & Total myricetin aglycons & 19 & Galloyl dimer & & & & & & \\
\hline 20 & Total quercetin glycosides & 20 & Procyanidin tetramer & & & & & & \\
\hline 21 & Total quercetin aglycons & 21 & Total flavan-3-ols & & & & & & \\
\hline 22 & Total kaempferol glycosides & 22 & Total procyanidins & & & & & & \\
\hline 23 & Total kaempferol aglycons & 23 & Total prodelphinidins & & & & & & \\
\hline \multirow[t]{6}{*}{24} & Total isorhamentin aglycons & 24 & Total procyanidin monomers & & & & & & \\
\hline & & 25 & Total procyanidin dimers & & & & & & \\
\hline & & 26 & Total procyanidin trimers & & & & & & \\
\hline & & 27 & Total procyanidin tetramers & & & & & & \\
\hline & & 28 & Total procyanidin pentamers & & & & & & \\
\hline & & 29 & Total galloylated flavan-3-ols & & & & & & \\
\hline
\end{tabular}

din, peonidin and malvidin 3-O-glucosides), flavonols (myricetin, quercetin and kaempferol), flavanols (catechin, gallocatechin, epicatechin gallate, dimer $\mathrm{B}_{2}$ and trimer epicatechin-4,8-epicatechin4,8-catechin) and phenolic acids (3,4-dyhydroxybenzoic acid and 4-hydroxycinnamic acid). Anthocyanins were purchased from Polyphenols Labs. (Sandnes, Norway). Myricetin, kaempferol, gallocatechin and epicatechin gallate were purchased from Extrasynthèse (Genay, France). Quercetin, catechin, 3,4-dyhydroxybenzoic acid and 4-hydroxycinnamic acid were purchased from Sigma (Steinheim, Germany). Procyanidin dimer and trimer were obtained in our laboratory in accordance with Escribano-Bailón et al. [25].

The total content of the different groups of phenolic compounds studied was calculated from the sum of the individual concentrations obtained for each individual compound, expressed in $\mathrm{mg} \mathrm{L}^{-1}$ of wine.

\subsection{Mean degree of polymerisation ( $m D P$ )}

The mean degree of polymerisation of wine flavanols was calculated in accordance with the method described by GonzálezManzano et al. [26].

\subsection{Copigmentation}

The contribution of the copigmentation phenomenon to the absorbance at $520 \mathrm{~nm}$ of the wines (\% copigmentation) was determined in accordance with the method proposed by Boulton [4] using a Hewlett Packard UV-vis HP-3853 spectrophotometer.

\subsection{Analysis of the chromatic parameters}

A Hewlett Packard UV-vis HP3853 was used for scanning between 380 and $770 \mathrm{~nm}$ at $2 \mathrm{~nm}$ intervals with a $2 \mathrm{~mm}$ pathlength quartz cell, and CIE $196410^{\circ}$ standard observer and the CIE $D_{65}$ illuminant observer, as references to calculate the tristimulus values recommended by the "Comission Internationale de l'Éclairage" [27]. The CIELAB and CIELUV colour spaces were used and parameters measured included: lightness $\left(L^{*}\right)$, hue $\left(h_{a b}\right)$, redgreen coordinate $\left(a^{*},-a^{*}\right)$ and yellow-blue coordinate $\left(b^{*},-b^{*}\right)$, Chroma $\left(C^{*}{ }_{a b}\right)$ and saturation $\left(s^{*} u v\right)$. Calculations were made using the CromaLab ${ }^{\circledR}$ software [28].

\subsection{Chemometric analysis}

Chemometric tools could be divided into quantitative and qualitative methods. The latter could be subdivided into supervised and unsupervised pattern recognition tools. Unsupervised methods are applied as a preliminary stage prior to supervise modelling, such as classification, so as to observe trends in the data indicating relationships between samples and between variables. Supervised pattern recognition methods usually indicate whether samples fall into pre-defined groups, how well, and what causes this separation. The human capability of visually recognising regularities in data is still unsurpassed by these computer methods $[8,9]$.

The SPSS 13.0 for Windows software package (SPSS, Inc., Chicago, IL) was used for data processing. The unsupervised pattern recognition method used for data analysis was principal components analysis (PCA), which was applied from the correlation matrix of the original variables. The supervised pattern recognition method was linear discriminant analysis (LDA). Stepwise feature selection was employed to select the most significant variables for 
$\mathbf{A}$

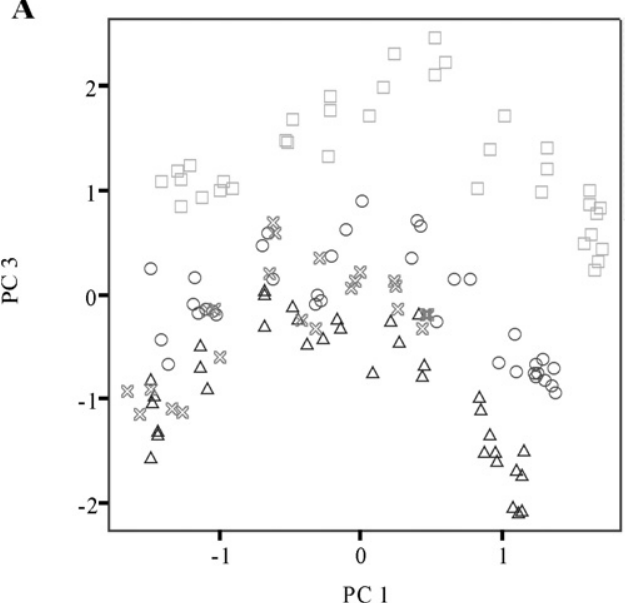

C

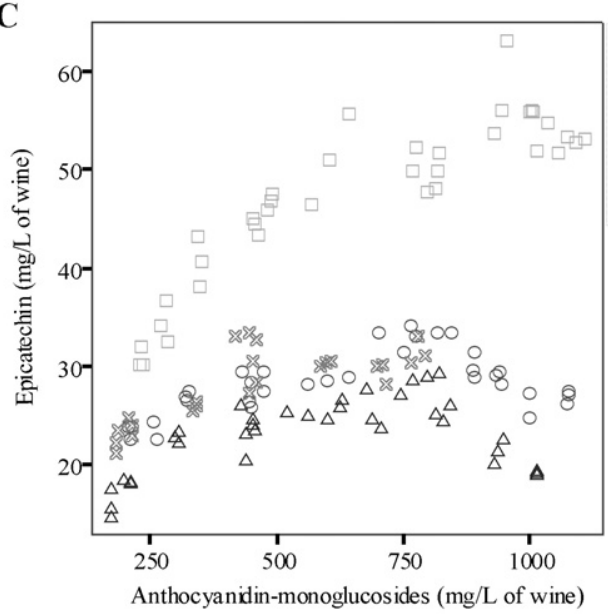

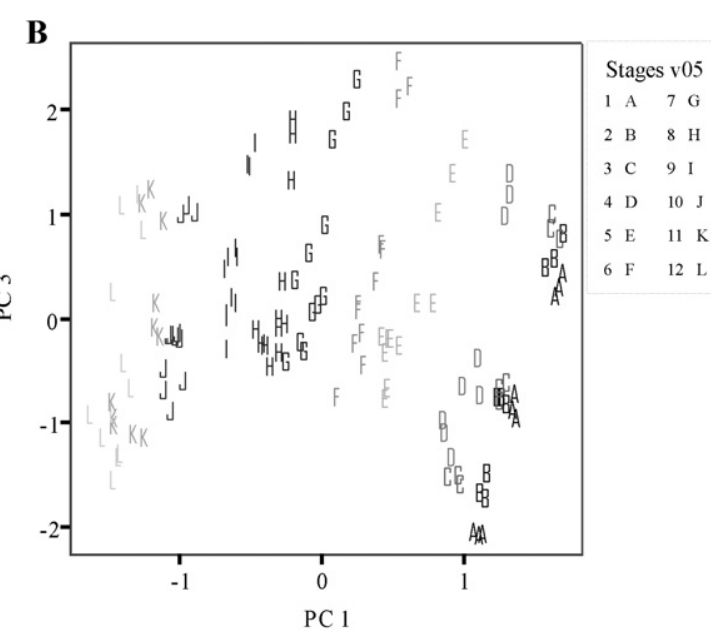

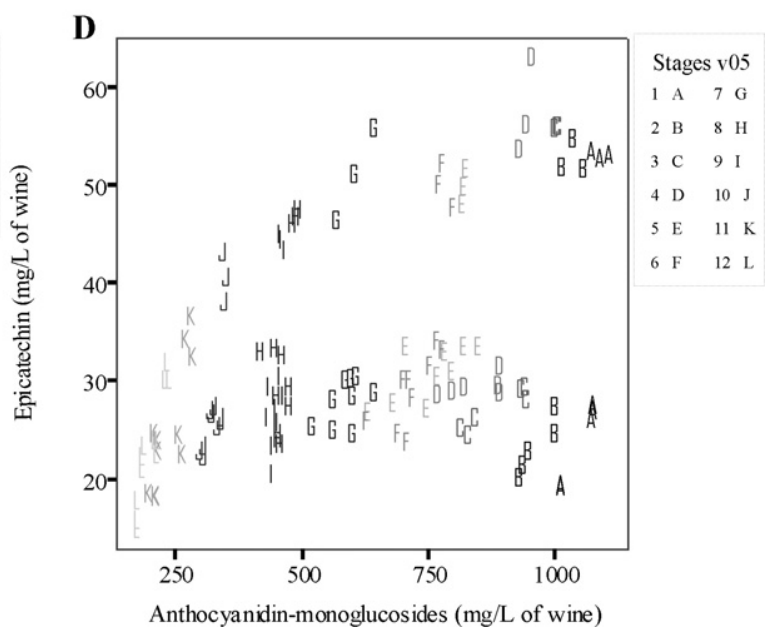

Fig. 1. Representation of the wine samples (2005 vintage) on the plane defined by the first and third principal components, PC 1 (41.6\%) and PC 3 (9.4\%) (A and B) and representation of the wine samples on the plane defined by epicatechin and anthocyanidin-monoglucosides (C and D). Differences between wines (A and C). Differences between stages in the winemaking process ( $\mathrm{B}$ and $\mathrm{D})$.

the discrimination between classes using F-statistic to test the significance of the change in Wilks' Lambda by adding or removing a variable. The prediction ability was estimated considering the percentage of samples adequately classified by the rules developed with the training set using a leave-one-out cross-validation procedure. The total variables used were 143 , corresponding to detailed phenolic composition, colour parameters, mDP, \% copigmentation and $\mathrm{pH}$. They are summarised in Table 2 (pigments) and Table 3 (other variables).

\section{Results and discussion}

\subsection{Principal component analysis}

Principal component analysis was used as an unsupervised pattern recognition method with the dataset from the 2005 vintage. Fig. $1 \mathrm{~A}$ and $\mathrm{B}$ shows the projection of the wine samples on the plane defined by the first and third principal components. The first principal component (PC 1) describes $41.6 \%$ of the variability in the data and the third (PC 3) 9.4\%. Although the second component (PC 2) accounts for $14.6 \%$ of the variability in the data, it is not represented since no easy to explain tendency was found for it. This might be due to this component is influenced by factors for which no related information was available. PC 3 allows distinction between $\mathrm{T}$ (placed below) and $\mathrm{G}$ (placed above), whereas $\mathrm{M}$ and $\mathrm{W}$ wines are located between them and they are hardly distinguishable (Fig. 1A). PC1 allows the visualisation of differences between stages of the winemaking process (Fig. 1B). From the obtained loadings, the variables most related with PC 3 and PC 1 were the contents of epicatechin and anthocyanidin-monoglucosides, respectively. Fig. 1C and $\mathrm{D}$ shows the plots of wine samples considering only these variables. In this plot, $\mathrm{T}$ and $\mathrm{G}$ can also be distinguished whereas $\mathrm{M}$ and $\mathrm{W}$ wines are located between them in a similar way to that shown in Fig. $1 \mathrm{~A}$ and $\mathrm{B}$, which indicates the high relation between the aforementioned variables and PC 1 and PC 3, respectively.

Similar results were obtained with the dataset from the 2006 vintage, in this case, the projection of the wine samples on the plane defined by the first and second principal components PC 1 (38.3\%) and PC 2 (19.9\%) (Fig. 2A and B) shows a similar pattern to the 2005 vintage plot, as stated above the variable most related with PC 1 was the content of anthocyanidin-monoglucosides which is related to stages of the winemaking process (Fig. 2B). PC 2 allows distinction between wines (Fig. 2A) and the variable most related to this $\mathrm{PC}$ was the content in the flavonol quercetin. The plots using the anthocyanidin-monoglucosides and quercetin contents are also presented (Fig. 2C and D); these plots show a similar distribution pattern to those in Fig. 2A and B and they are also similar to the plots obtained for the 2005 vintage. It is noticeable that in 2006 the differences between wines are related to PC 2, thus a greater amount of data variability than in vintage 2005 was related to the type of wine.

In order to increase the variability, the samples from both vintages, 2005 and 2006, were used in a new PCA analysis. The plot of 
A

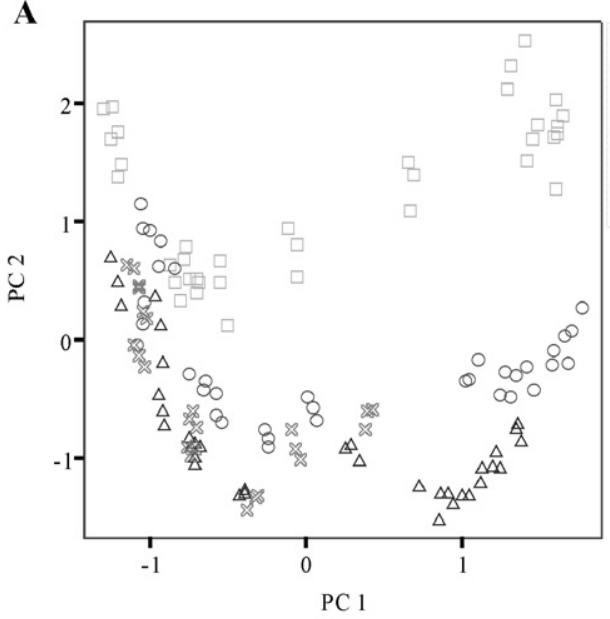

C

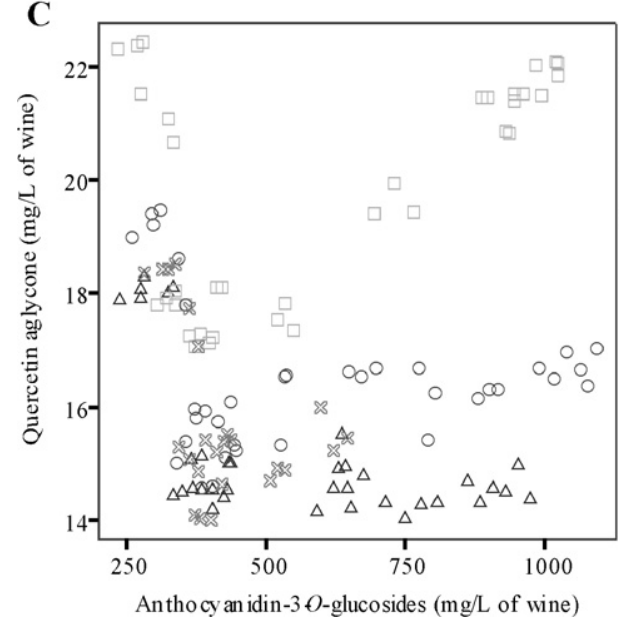

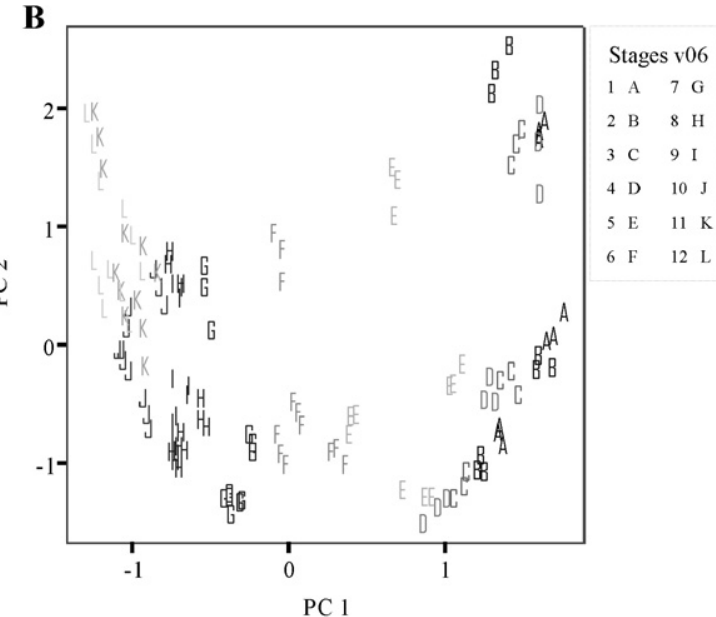

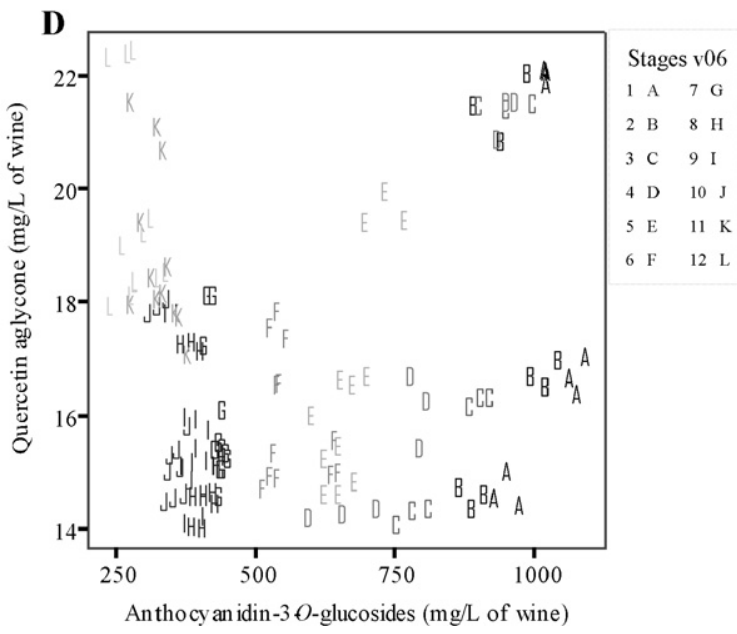

Fig. 2. Representation of the wine samples (2006 vintage) on the plane defined by the first and third principal components, PC 1 (38.3\%) and PC 2 (19.9\%) (A and B) and representation of the wine samples on the plane defined by quercetin aglycone and anthocyanidin-monoglucosides (C and D). Differences between wines (A and C). Differences between stages in the winemaking process (B and $\mathrm{D})$.

the wine samples in the space defined by PC 1 (31.3\%), PC 2 (18.6\%) and PC $3(11.7 \%)$ shows differences between the wines and stages in the winemaking process (Fig. 3A and B). However, in this case, another and more intense pattern was also observed related to the vintage that allowed a clear distinction between the wines of 2005 and 2006 vintages. Fig. $3 \mathrm{C}$ emphasises this pattern showing the plane defined by PC 1 and PC 2. In general, the principal components PC 1, PC 2 and PC 3 stand for the differences between stages of the winemaking process, vintages and types of wines, respectively. From the obtained loadings the variables most related to these PCs were the content of malvidin-3-O-glucoside followed by total anthocyanidin-monoglucosides' contents, for PC1, which also made a great contribution in the models where the 2005 and 2006 vintages were considered separately. For PC 3 the most related variable was the total content of pyranoanthocyanidins, and for PC 2 the total content of anthocyanidin-diglucosides. Anthocyanidindiglucosides are minor anthocyanins in $V$. vinifera although in recent years they have been extensively found in grapes and wine from this species $[3,6,29,30]$. The fact that in our study their contents allow the distinction between vintages seems to indicate that their variations in grapes (and consequently in wines) are related to weather conditions.

In the three PCA analyses performed, the variations in the contents of anthocyanidin-monoglucosides play a decisive role for distinguishing between different stages of the winemaking. The changes in the amount of these compounds during the winemaking process can be related to their involvement in the formation of new pigments (including pyranoanthocyanidins) or to their degradation by oxidative or enzymatic processes [31-33].

Polyphenols whose variations allow the distinction between the different wines were not the same in all of the PCA analyses performed (i.e. epicatechin in 2005, quercetin in 2006 and pyranoanthocyanidins in $2005+2006$ ). This could be attributed to the different phenolic composition of the grape in each vintage. Differences between the polyphenolic profiles of a given cultivar reflects to a great extent its genetic potential but environmental stimuli also play critical roles in polyphenols' biosynthesis and this effect is reflected in the polyphenolic profiles [18].

\subsection{Linear discriminant analysis}

Linear discriminant analysis was performed as a supervised pattern recognition method with the dataset from the 2005 vintage so as to allocate the wine samples to their wine group. Thirtyone variables were retained that allowed $100 \%$ of the samples were correctly classified in both the internal and leave-one-out cross-validation procedures. The most represented family was flavan-3-ols with eleven variables that correspond to this family of phenolic compounds. A new LDA model was developed using only these eleven variables in order to use a single family of compounds as classifiers. Using this approach $100 \%$ of samples were correctly classified in internal validation and $96.2 \%$ in the leave-one-out 

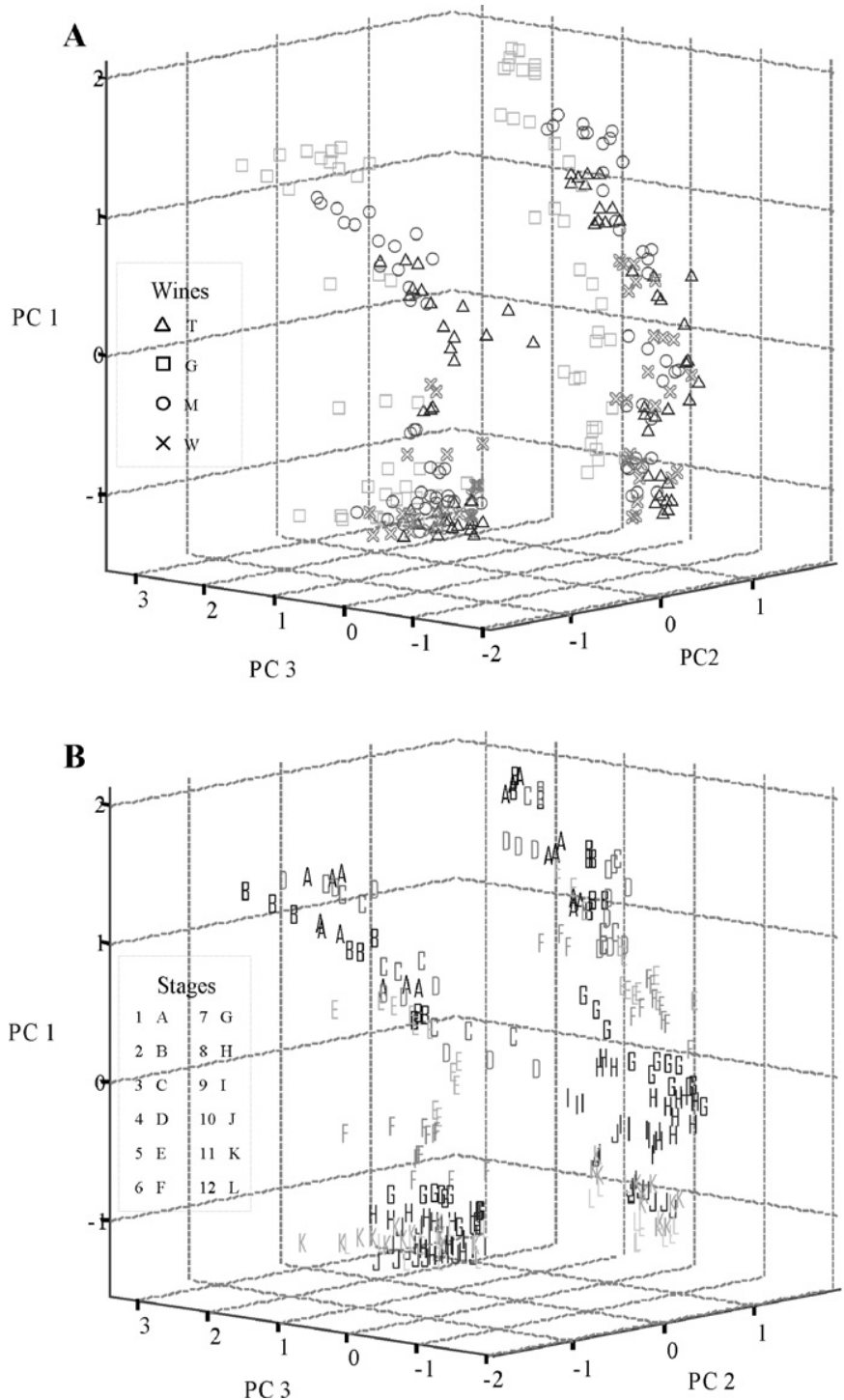

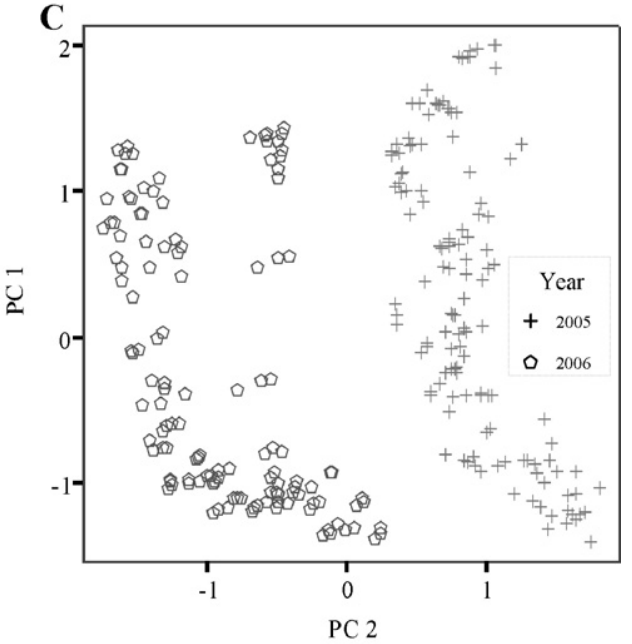

Fig. 3. Representation of the wine samples in the space defined by the first, second and third principal components, PC 1 ( $31.3 \%)$, PC 2 (18.6\%) and PC 3 (11.7\%) (A and B) and in the plane defined by PC 1 and PC 2 (C) (2005 and 2006 vintages together). (A) Differences between wines. (B) Differences between stages in the winemaking process. (C) Differences between vintages.

cross-validation procedure. Using the variables corresponding to other phenolic families, the percentage of samples correctly classified was lower in all cases. The same procedure was applied to the dataset from the 2006 vintage. Forty-one variables were retained, which allowed $100 \%$ of samples were correctly classified in both the internal and leave-one-out cross-validation procedures. The most represented family was also flavan-3-ols with twelve variables that were used to develop a new LDA model, in which $91.7 \%$ of samples were correctly classified in the internal validation and $85.6 \%$ in the leave-one-out cross-validation procedure. Similarly, when variables of the rest of the families were used the percentage of samples correctly classified was lower in all cases. In the case of the 2005 and 2006 vintages together, fifty-four variables were retained, and $100 \%$ of samples were correctly classified in the internal validation and $98.5 \%$ in the leave-one-out cross-validation procedure (Fig. 4). The most represented family was again flavan3-ols with sixteen variables (Table 3 , variables $1,2,5,7-10,12$, $14-17,19,20,23$ and 24). An LDA model was developed using only these variables: $82.4 \%$ of samples were correctly classified in the internal validation and $79.0 \%$ in the leave-one-out cross-validation procedure. Again, worse classification results were obtained using variables of other phenolic families.

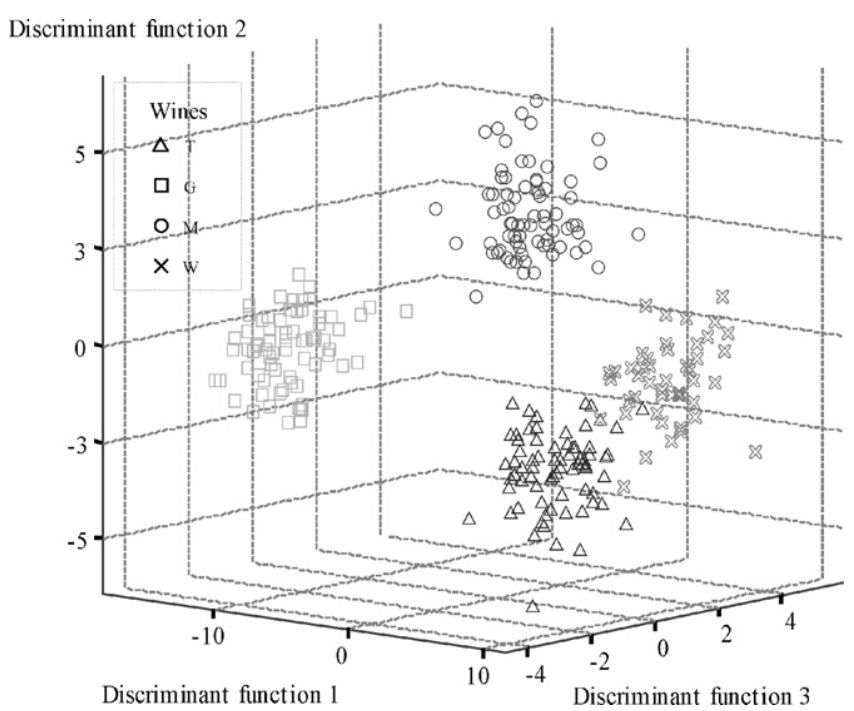

Fig. 4. Representation of the wine samples in the space defined by the first, second and third discriminant functions (2005 and 2006 vintages together). 
It appears that flavan-3-ols are predominant factors regarding differentiation between T, G, M and W wines. Flavan-3-ol composition is dependent on the ripeness stage and growth conditions, but it is also greatly affected by genetics $[18,34]$. This group of flavonoids was also utilised in order to classify wines according to their geographical origin [17], cultivars [20] or both [18]. In the present study the generated models have permitted discrimination not only between different cultivars ( $T$ and $G$ wines), but also between different oenological practices ( $\mathrm{M}$ and $\mathrm{W}$ wines). Therefore, the different procedures used for the winemaking of $\mathrm{M}$ and $\mathrm{W}$ wines (mixing grapes or blending wines) would imply important differences related to the qualitative and/or quantitative phenolic profile, which are mainly reflected in the flavanols composition. Although other families of compounds or more easily obtained parameters, such as colour parameters, have been separately evaluated, in all cases the results obtained were not as good as using flavan-3-ol compounds.

\section{Conclusions}

Based on the results obtained it can be concluded that patterns related to stages of the winemaking process, type of wines and vintages can be differentiated using principal component analyses. Moreover, the variables most related to the principal components obtained in these analyses have been identified, which provide a chemical explanation of the observed tendencies.

Furthermore, linear discriminant analysis has been applied in order to classify the samples of the different studied wines (T, G, M and $\mathrm{W}$ ). The generated models have permitted discrimination not only between different cultivars ( $\mathrm{T}$ and $\mathrm{G}$ wines) wines, but also between different oenological practices ( $\mathrm{M}$ and $\mathrm{W}$ wines). From the 143 considered variables, flavan-3-ols have proved to be the most profoundly influential for wine differentiation.

\section{Acknowledgements}

Thanks are due to the Spanish MICINN and FEDER (Projects ref. AGL2005-07245-C03-01 and AGL2008-05569-C02-01) and to the Junta de Castilla y León (Grupo de Investigación de Excelencia (GIP/USAL), GR133) and to the Consolider-Ingenio 2010 Programme (FUN-C-FOOD, CSD2007-00063) for financial support. The authors also thank Bodegas RODA S.A. (Haro, La Rioja, Spain) for supplying the wine samples.

\section{References}

[1] M. Monagas, V. Núñez, B. Bartolomé, C. Gómez-Cordoves, Am. J. Enol. Viticult. 54 (2003) 163-169.
[2] S. González-Manzano, M. Dueñas, J.C. Rivas-Gonzalo, M.T. Escribano-Bailón, C. Santos-Buelga, Food Chem. 114 (2009) 649-656.

[3] M. García-Marino, J.M. Hernández-Hierro, J.C. Rivas-Gonzalo, M.T. EscribanoBailón, Anal. Chim. Acta 660 (2010) 134-142.

[4] R. Boulton, Am. J. Enol. Viticult. 52 (2001) 67-87.

[5] R. Brouillard, O. Dangles, Food Chem. 51 (1994) 365-371.

[6] C. Alcalde-Eón, M.T. Escribano-Bailón, C. Santos-Buelga, J.C. Rivas-Gonzalo, Anal. Chim. Acta 563 (2006) 238-254.

[7] D.L. Massart, B.G.M. Vandeginste, L.M.C. Buydens, S.D. Jong, P.J. Lewi, J. SmeyersVerbeke, Handbook of Chemometrics and Qualimetrics , Elsevier Science Inc., 1998.

[8] R.G. Brereton, Chemometrics: Data Analysis for the Laboratory and Chemical Plant, J. Wiley, Chichester, West Sussex, England, 2003.

[9] B.G.M. Vandeginste, D.L. Massart, L.M.C. Buydens, Handbook of Chemometrics and Qualimetrics: Part B , Elsevier Science Inc., 1998.

[10] D.M.A.M. Luykx, S.M. Van Ruth, Food Chem. 107 (2008) 897-911

[11] L.A. Berrueta, R.M. Alonso-Salces, K. Héberger, J. Chromatogr. A 1158 (2007) 196-214.

[12] J. Saurina, Trac-Trends Anal. Chem. 29 (2010) 234-245.

[13] L. Almela, S. Javaloy, J.A. Fernández-López, J.M. López-Roca, J. Sci. Food Agric 70 (1996) 173-180.

[14] B. Berente, D. De la Calle García, M. Reichenbächer, K. Danzer, J. Chromatogr. A 871 (2000) 95-103.

[15] C. Santos-Buelga, S.S. Muñoz, Y. Gutierrez, E. Hebrero, J.L. Vicente, P. Galindo, J.C. Rivas-Gonzalo, J. Agric. Food Chem. 39 (1991) 1086-1090.

[16] S. Pérez-Magariño, M. Ortega-Heras, M.L. González-San José, Z. Boger, Talanta 62 (2004) 983-990.

[17] M.A. Rodríguez-Delgado, G. González-Hernández, J.E. Conde-González, J.P. Pérez-Trujillo, Food Chem. 78 (2002) 523-532.

[18] D.P. Makris, S. Kallithraka, A. Mamalos, Talanta 70 (2006) 1143-1152.

[19] S. Kallithraka, A. Mamalos, D.P. Makris, J. Agric. Food Chem. 55 (2007) 3233-3239.

[20] A. de Villiers, P. Majek, F. Lynen, A. Crouch, H. Lauer, P. Sandra, Eur. Food Res. Technol. 221 (2005) 520-528.

[21] E. Gomez-Plaza, R. Gil-Muñoz, J.M. Lopez-Roca, A. Martínez, Food Res. Int. 32 (1999) 503-507.

[22] C. Gómez-Cordovés, M.L. Gónzalez-Sanjosé, J. Agric. Food Chem. 43 (1995) 557-561.

[23] M. García-Marino, C. Santos-Buelga, J.C. Rivas-Gonzalo, M.T. Escribano-Bailón, Semana Vitivinícola 3248 (2009) 6-14

[24] M. García-Marino, J.C. Rivas-Gonzalo, E. Ibanez, C. Garcia-Moreno, Anal. Chim. Acta 563 (2006) 44-50.

[25] M.T. Escribano-Bailón, Y. Gutierrez-Fernandez, J.C. Rivas-Gonzalo, C. SantosBuelga, J. Agric. Food Chem. 40 (1992) 1794-1799.

[26] S. González-Manzano, C. Santos-Buelga, J.J. Pérez-Alonso, J.C. Rivas-Gonzalo, M.T. Escribano-Bailón, J. Agric. Food Chem. 54 (2006) 4326-4332.

[27] M. Melgosa, E. Hita, A.J. Poza, D.H. Alman, R.S. Berns, Color Res. Appl. 22 (1997) $148-155$.

[28] F.J. Heredia, C. Álvarez, M.L. Gonzalez-Miret, A. Ramirez, in: CromaLab, análisis de color. Registro General de la Propiedad Intelectual SE-1052-04, Sevilla, Spain, 2004.

[29] A. Baldi, A. Romani, N. Mulinacci, F.F. Vincieri, B. Casetta, J. Agric. Food Chem 43 (1995) 2104-2109.

[30] A. Heier, W. Blaas, A. Droß, R. Wittkowski, Am. J. Enol. Viticult. 53 (2002) 78-86.

[31] M.V. Moreno-Arribas, C. Polo, Wine Chemistry and Biochemistry , Springer, New York, NY, 2009.

[32] R.L. Jackman, R.Y. Yada, M.A. Tung, R.A. Speers, J. Food Biochem. 11 (1987) 201-247.

[33] H. Li, A. Guo, H. Wang, Food Chem. 108 (2008) 1-13.

[34] J.A. Kennedy, Y. Hayasaka, S. Vidal, E.J. Waters, G.P. Jones, J. Agric. Food Chem. 49 (2001) 5348-5355. 